\title{
THE USE OF MOBILE APPLICATION TO SUPPORT SPEECH DELAY CHILDREN IN MALAYSIA: A PRELIMINARY STUDY
}

\author{
Mariam Mohamad
}

Universiti Sains Malaysia, Malaysia

\begin{abstract}
This study explores the use of mobile application to support children with speech delay in Malaysian community. Currently, there are various commercial mobile applications to support speech delay among English speakers, however, there is a gap in the development of mobile application catered specifically for Malay language speakers. The paper reports the preliminary study of the research project by exploring the possibility of utilizing the mobile application to support the children. The research design of this study is qualitative and based on case study methodology. Data collection methods include observation of the special need children's use of mobile application as well as interviews with parents. Nvivo will be used to analyze the data. This study applies a two-pronged approach to contribute to the body of knowledge in the field of mobile learning and special need education in Malaysian schools. The study successfully developed a mobile application to support speech delay children, and also brings added value in understanding the situation regarding the use of mobile application to support children with special need. These are significant areas which have been established in this study to shed light on the issues associated with the use of mobile application for special needs children.
\end{abstract}

Keywords: mobile application, speech delay, Malaysia, mobile learning, assistive technology

\section{INTRODUCTION}

In general, a child is considered to have a speech delay if the child's speech development is significantly below the norm for children of the same age (Leung \& Kao, 1999). There are various causes of speech delay which may include mental retardation, hearing loss, maturation delay, expressive language disorder, bilingualism, psychosocial deprivation, autism, elective mutism, receptive aphasia and cerebral palsy. In this study, concentration is given to a case of simple developmental speech delay. Simple developmental speech delay as defined by McRae \& Vickar (1991) is a type of speech delay which have no relation to the causes as stated by Leung \& Kao (1999). Normally, for children with simple developmental delay, the causes are unknown, yet the speech is minimal or may be no speech at all.

Speech and language delay in children commonly have difficulty with articulation, pronunciation, expressive vocabulary and comprehension

difficulties (Woo \& Teoh, 2007). These children as reported as do not speak as well as other children their age (Leung \& Kao, 1999). On reflection, there is a concern that these children might have difficulties in learning and it could impact on their future as well. In a research conducted in Malaysia by Tan \& Yadav (2008), among 900 samples of children with disability, there are 68 children with speech delay problems. Intervention ought to be provided through various platforms, and one potential medium is through the mobile application.

The Ministry of Education, Malaysia has highlighted the importance of special education under the Special Education Integration Program (Mohd Yusuf et al, 2014). In addition, the Ministry of Education, Malaysia also stressed the need of embedding Information Communication 
Technology (ICT) in supporting school children (Malaysia Education Blueprint 2013-2025) and higher education students (Arokiasamy, 2012). Given the importance of special education and the use of ICT in Malaysian schools and higher institutions, there are studies conducted by Malaysian scholars regarding the integration of ICT in special needs education at both levels. In a review by Mohamad \& Phung (2015), with the concentration on mobile application, there are 14 academic papers published by the Malaysian academics in the area of mobile assistive technology. There are 5 studies respectively for autistic and dyslexic learners, 3 studies related to own syndrome learners and 1 study related to slow learners. However, there are no studies related to speech delay was identified in the review.

On the other hand, globally, there are existing studies related to the development of mobile applications for speech delay in children. Song \& Yusof (2010) conducted a review on the application of mobile technology for special needs children through the use of smart phones and I-pods. In Romania, technology intervention is used in speech disorder therapy (Danubianu, Tobolcea and Pentiuc, 2009). There are also commercial applications such as Speech with Milo (Speech with Milo Official Website) and Hamaguchi Apps (Hamaguchi Apps Official Website) for speech delay children among the English speakers. However, there is no existence of an application to help children with speech delay to learn Malay language. This was confirmed by a speech therapist from Penang General Hospital. Therefore, the study looks into the possibility of the use of mobile application specifically to support children with speech delay problem among the Malay speakers.

This paper explores the preliminary study of the use of mobile application known in the context of Malay language. It will begin with a section to outline the research design. The next section continues with the findings and discussion before concluding the paper.

\section{RESEARCH METHODOLOGY}

The research design of this study is qualitative and based on a case study methodology to explore the use of mobile application to support speech delay children. Data collection includes observation during the use of mobile application as well as interviews with parents. Nvivo are used to analyze the data collected in the study. In the study, validity and reliability are emphasized. Validity is ensured through sampling strategy. Participants are chosen based on the rationale that they would fulfill the purpose of the study. On the other hand, reliability is ensured by following the research procedure, the observation and interview.

In this study, a mobile application entitled MASSDEC (Mobile Application to support speech delay children) was developed for speech delay children learning basic Malay language vocabularies. The application consisted of five modules and was developed using ADDIE model. The modules include; Numbers, Fruits, Colors, Transport and Animals. At the end of each module there are quizzes to support the learners. The application was developed using multimedia elements. The environmental impact on student learning and behavior should also be emphasized when teaching students with speech delay. The learning environment includes physical, sensory environment and the surrounding area. The following table illustrates some of the interface included in the application 
Table 1: Main interface in MASSDEC application

This is the main interface in MASSDEC application. The screen displayed beautiful scenery and attractive pictures to grab children's attention. Buttons are provided to enter the main menu of the application.

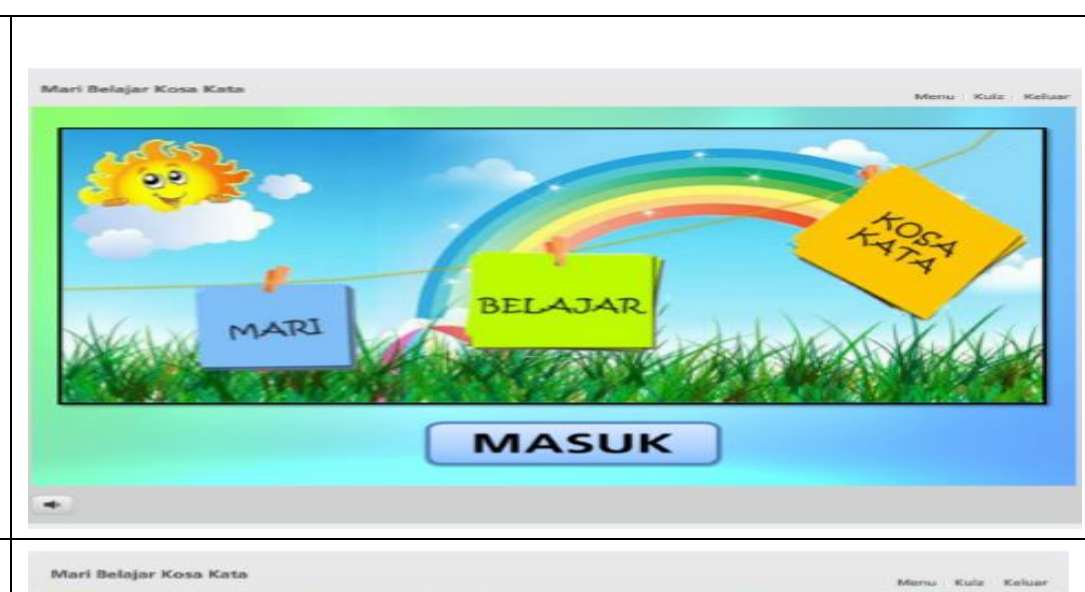

This is the second interface in MASSDEC application. The interface has menu to enable the users to select modules that they want to explore.

This is one of the interface for module 1: Number. User can explore how to pronounce vocabularies related to numbers in Malay. Audio sound to support explanation was also provided.

This is one of the interface for module 2: Fruits. User can explore how to pronounce vocabularies related to fruits in Malay. Audio sound to support explanation was also provided.

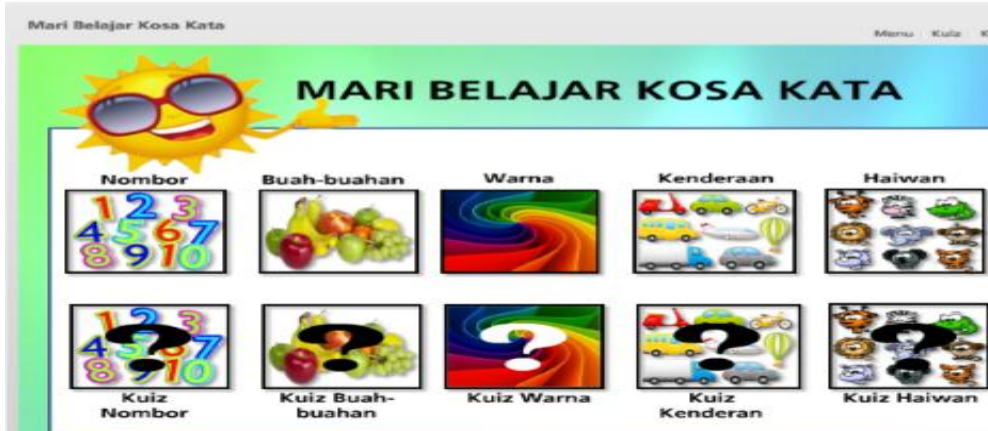

$+$
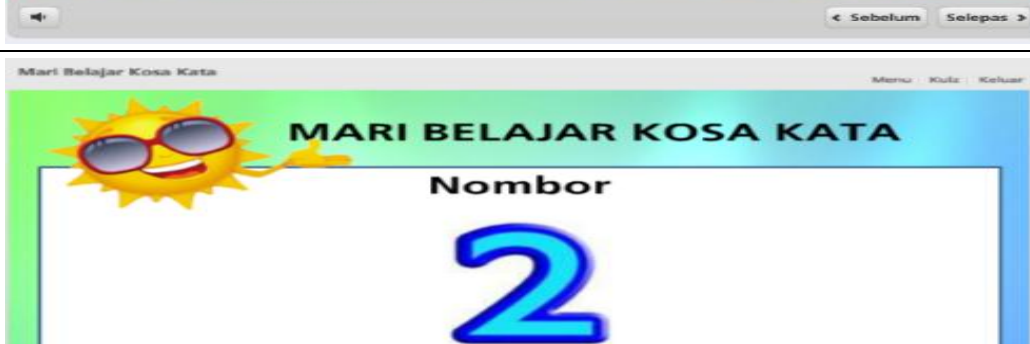

du $+a=$ dua

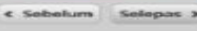

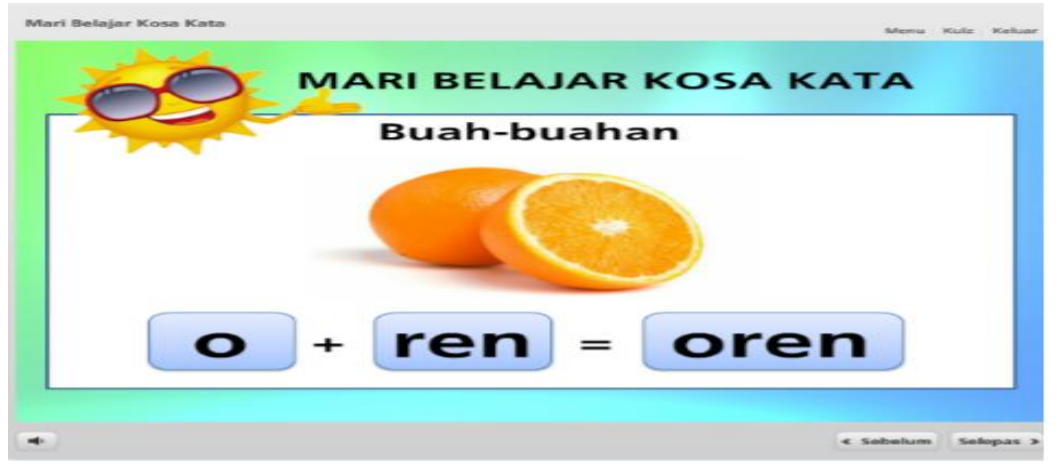




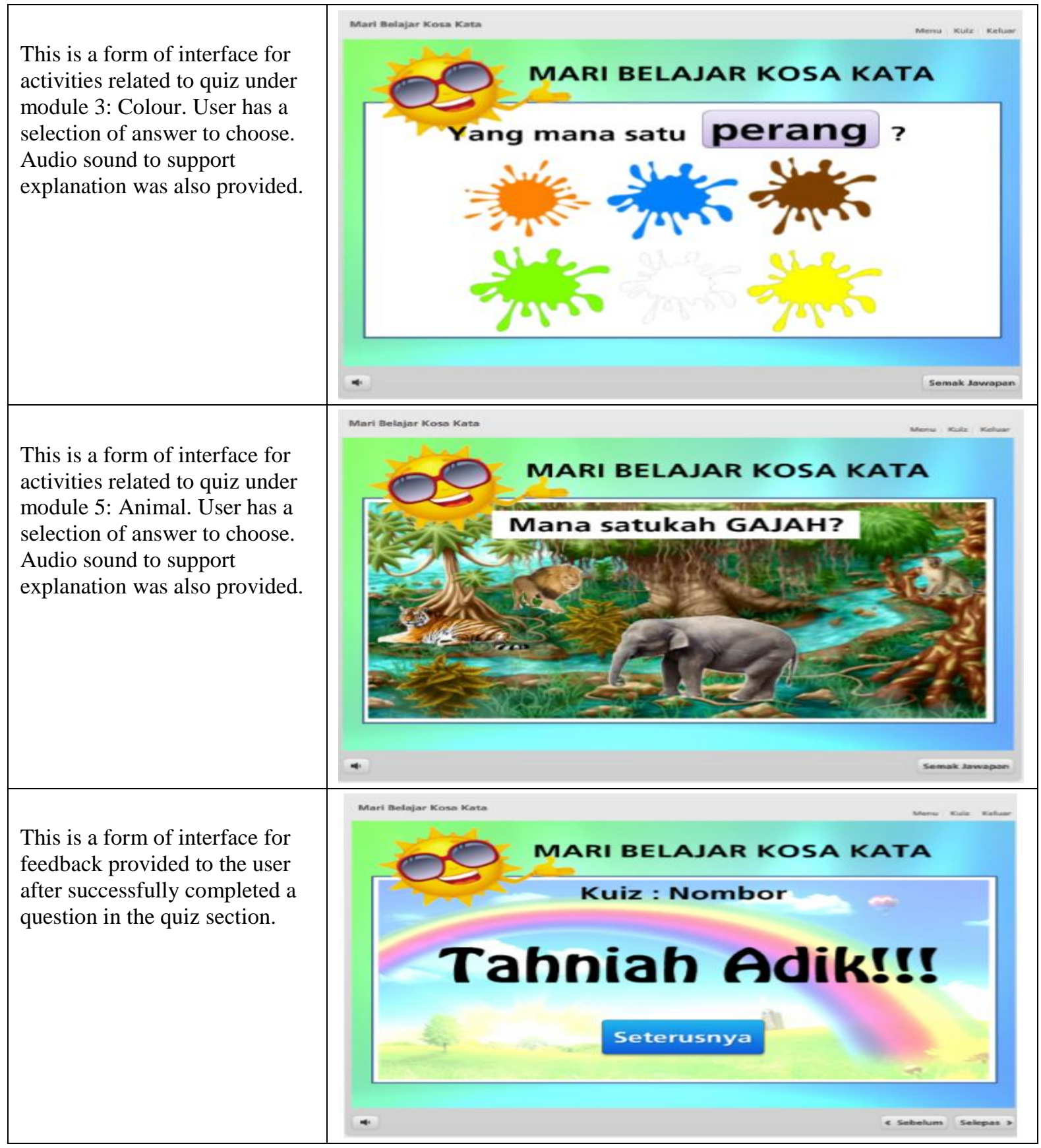

\section{FINDINGS AND DISCUSSION}

The paper reports the preliminary study, which consisted of evaluation by experts, followed by a pilot study which include observation and interview with the parent. The evaluation was conducted by consulting two experts in multimedia design. The expert review was obtained through semi structured interviews to get the opinion about the usability of the application. Both experts were invited to use the application and to check it thoroughly. After the usability test, they were invited for an interview to obtain their recommendations. Interview schedule was constructed based on the checklist for multimedia instructional design (Keller \& Suzuki, 1988) which covers the following items; title screen, introduction, menu structure, information presentation and learning guidance, practice and feedback as well as evaluation and ending. The following table describes the important aspects that were covered in the checklist: 
Table 2: Checklist for multimedia instructional design (Keller \& Suzuki, 1988

\begin{tabular}{|l|}
\hline Title screen \\
Capture user's attention? \\
Related to the content of the material? \\
Not forcing users to view long animation? \\
\hline Introduction \\
Give users the feeling "This is for me!'? \\
Objectives are clearly stated, easy to understand? \\
State usefulness and values of attaining objectives? \\
Users can judge if they have prerequisites? \\
Give review opportunities for prerequisites? \\
\hline Menu structure \\
Provide a menu so that users can select order of learning? \\
Overall structure is clear to the users? \\
Divided into short sections to prevent boredom? \\
Users know how much they finished and how much more to complete? \\
Sections the users finished are marked as completed? \\
Advices are given when users have options to select? \\
Menu can be accessed soon after starting? \\
\hline Information presentation and learning guidance \\
Not page after page information presentation consecutively? \\
Ask questions to motivate the users from time to time? \\
Order the contents from easy to more difficult? \\
Users can detect weak points from early stages? \\
Have adequate concreteness with familiar examples an illustrations? \\
\hline Practice and feedback \\
Provide practice opportunities in risk-free situations? \\
Informational feedback are given for wrong answers? \\
Affective feedbacks are given for correct answers? \\
No negative/critical feedbacks for wrong answers? \\
No interesting feedbacks for wrong answers? \\
Chances for re-try are given? \\
Position users' success in a bigger picture (future advances)? \\
Provide immediate opportunities to apply knowledge/skill that user just mastered? \\
\hline
\end{tabular}

With regard to the title screen, both experts agreed that the title screen fulfilled the criteria to capture the user's attention. However, the first expert suggests that there is a need for informing prerequisites for the users. Therefore, the prerequisites were informed in the installation manual of the application. Both experts also agreed that the overall structure is clear to the user. In addition, one of the experts also proposes to add variation to the quizzes. Rather than linear quiz with a selection of answers, more open quiz are also included; for example in a quiz to find the animal. 
It was also recommended by one of the experts to add "next" and "previous" button on every screen to allow flexibility in the navigation.

Upon refinement of the application, the study embarked into the pilot stage with a single case study. The child in the pilot stage is henceforth known as Ryan (not a real name). He is chosen for the pilot study because he is categorized as a speech delay child. He was diagnosed with a simple developmental speech delay. His speech development is considered not appropriate to his age. During the study, he was 7 years old, but has a 5 year old speech level. He mainly converses in English and have lack of Malay language vocabulary. Nevertheless, he is a vibrant and a bright child who likes to interact with other people.

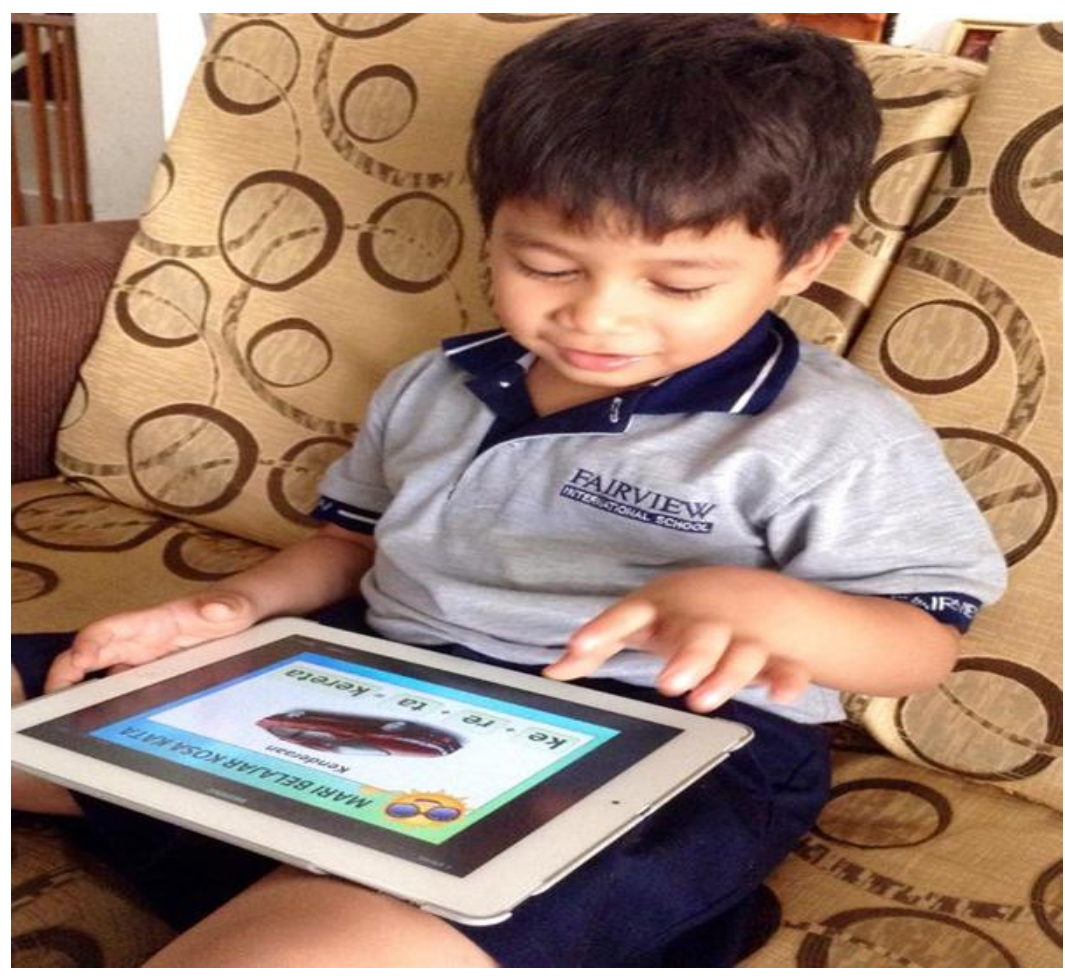

Figure 1: Ryan showed his interest during pilot study

With the help of parents, Ryan test the usability of the application. An analysis has been used to record all kinds of reactions when he interacts with the courseware. He showed positive impact with the use of the application. He also showed a positive behavior before, during and after using this application. This was evident when he was very excited and happy to be given this application. This application requires double touch (touch screen), not like other applications which only have one touch, but this does not become a problem with the help of the parent. Overall, it can be seen that he has mastered the modules in the application. He was able to pronounce correctly most of the vocabularies introduced in the modules. He could respond to the instruction provided. He also able to answer the quizzes.

With regard to the interview with the parents, Ryan's parent mentioned that Ryan began to show interest in learning after being shown the interactive part in the application. This suggests that the learning activity through mobile application is an effective technique for teaching children with special need. The interview below demonstrates that the mobile application is a learning tool that is suitable to be used by speech delay children.

"I see my son can use this application effectively. He can follow the module in the application properly. I believe that my son is interested in this 
application because the images and objects are interesting and the instruction given is also very clear. As he was familiar with I-pad, so learning through MASSDEC could eventually attract him. Very practical for a kid like him".

\section{CONCLUSION}

In this study, respondents showed positive improvement after undergoing the pilot study. Through this positive effect, it was found that the parents were also provided positive feedbacks that the use of this courseware can be used as an additional therapy or additional tool in the learning process for their children.

This study applies a two-pronged approach to contribute to the body of knowledge in mobile learning and special need education in Malaysia. The study does not only develop a mobile application to support speech delay children among the Malay speakers, but also adds value in understanding the situation regarding the use of mobile application to support children with special need. The study assists special education division under the Ministry of Education, Malaysia in introducing mobile application as an alternative tool for children with speech delay problem. As there is no existing mobile application to support children with speech delay among the Malay speakers, this study could be considered a groundbreaking attempt to provide the mechanism.

As the conclusion, this study has established that the use of mobile application with multimedia elements can be used as an additional tool to support speech delay children as it has the potential to increase the interest and attention of children with speech delay to learn. It is envisaged that the mobile application would have the potential to be used to support special need children in Malaysia.

\section{ACKNOWLEDGEMENT}

This study was conducted under the Short Term Grant of Universiti Sains Malaysia. The authors also wish to thank the co-researchers; Professor Balakrishnan Muniandy and Dr Aznan Che Ahmad. Also to the research assistant; Farah Waheeda Ariffin and all other people involved in the research.
At the end of the interview, Ryan's parent highlighted that she supported the use of this application which she believed has the potential to support speech delay children in Malaysia.

\section{REFERENCES}

Arokiasamy, A., 2012, Enhancing the Quality of Teaching at Higher Education Institutions in Malaysia through the Use of Information and Communication Technology (ICT). Australian Journal of Business and Management Research (AJBMR), 2 (4), 20-25.

Danubianu, M., Tobolcea, I., \& Pentiuc, S. G., 2009, Advanced Technology in Speech Disorder Therapy of Romanian Language. Journal of computing, 1(1).

Hamaguchi Apps (Hamaguchi Apps Official Website). Date of access: 23/5/2016. http://www.hamaguchiapps.com/first-phrases.html

Keller, J. M., And Suzuki, K., 1988, Use of the ARCS Motivation Model in Courseware Design. In D. H. Jonassen (ed.), Instructional Designs for Microcomputer Courseware. Hillsdale, N.J.: Erlbaum.

Leung, A. K. C. \& Pion Kao, C., 1999, Evaluation and Management of the Child with Speech Delay. American Family Physician. [Online] Date of access: 23/5/2016. http://www.aafp.org/afp/990600ap/3121.html

Malaysia Education Blueprint 2013-2025. Date of access: 23/5/2016. http://www.moe.gov.my/en/pelanpembangunan-pendidikan-malaysia-2013-2025

Mcrae, K. M. And Vickar, E., 1991, Simple Developmental Speech Delay: A Follow-Up Study. Developmental Medicine \& Child Neurology, 33, 868874

Mohd Yusof, A., Sarojini Daniel, E.G., Low, W.Y. \& Abdul Aziz, K., 2014, Teachers' perception of mobile edutainment for special needs learners: the Malaysian case, International Journal of Inclusive Education, DOI: 10.1080/13603116.2014.885595

Mohamad, M. \& Phung, L.F., 2015, Ray of Hope: A Review of Mobile Assistive Technology for Special Educational Need in Malaysia. Paper presented at the $8^{\text {th }}$ International Conference of Education, Research and Innovation, Seville, Spain, $16^{\text {th }}-18^{\text {th }}$ November 2015.

Song, H., \& Yusof, A. M., 2010, A Current Review of the Use of Mobile Technology to Enhance Learning and Communication among Children with Developmental Disabilities. Paper presented at the EDULEARN10 Conference, Barcelona, Spain.

(Speech with Milo Official Website). Date of access: 23/5/2016. http://www.speechwithmilo.com/

Tan, K.L, Yadav, H., 2008, Assessing the development of children with disability in Malaysia. Medical Journal of Malaysia 63(3):199-202

Woo, P. J., \& Teoh, H. J., 2007, An investigation of cognitive and behavioural problems in children with attention deficit hyperactive disorder and speech delay. Malaysian Journal of Psychiatry, 16(2), 50-58 